\title{
Persona yámbica: el caso de Arquíloco de Paros*
}

\section{(4) Sastián Eduardo Carrizo}

Centro de Estudios Helénicos - Universidad Nacional de Rosario (CEHel-

UNR), Argentina

carrizo_sebastian@hotmail.com

Recibido: 20/06/2018. Aceptado: 30/10/2018

\section{Resumen}

El objetivo del presente trabajo es examinar los modos en que el 'yo' se manifiesta en la poesía yámbica de Arquíloco de Paros (s. VII a.C.) y sus posibles funciones dentro de la performance poética. En particular, desde un análisis discursivo, se analizan las formas en que la primera y la segunda personas se inscriben deícticamente en los ff. 19, 122, 196 y 196aW, y las relaciones de identidad que se entablan entre los distintos actantes de los niveles enuncivo y enunciativo. En definitiva, se concluye que es posible observar un proceso de enmascaramiento del 'yo' ligado, probablemente, a la crítica y a la invectiva yámbica.

\section{Iambic persona: the case of Archilochus of Paros}

\begin{abstract}
The aim of this paper is to examine the ways in which the poetic speaker manifests itself in the iambic poetry of Archilochus of Paros (7th century BC) and its possible functions within the poetic performance. In more specific terms, from a discursive analysis, we analyze the ways in which the first and the second person are deictically inscribed in ff. 19, 122, 196 and 196aW, and the identity relations that are established between the different actants of the enuncive and enunciative levels. In short, it is concluded that it is possible to observe a process of masking the poetic speaker linked, probably, to criticism and iambic invective.
\end{abstract}

\section{Palabras clave}

Arquíloco poesía yámbica arcaica máscara invectiva persona loquens

\section{Keywords}

Archilochus ancient iambic poetry mask invective persona loquens 
1. El inicio de este debate podría retrotraerse al escepticismo expresado por Dover (1964:183-212), en su intervención en la Fondation Hardt, acerca de la deducción autobiográfica del 'yo' en la poética de Arquíloco. Posteriormente, de Dover, postulará su hipótesis de los "stock characters" y su interpretación del 'yo' en Arquíloco enmarcado dentro del contexto ritual del yambo. Específicamente para un relevamiento de esta discusión y de las posturas enfrentadas, véanse Rösler (1985:131-144) y Slings (1990). Para la crítica de la interpretación autobiográfica de los poetas arcaicos, véanse Tsagarakis (1977); Nagy (1976:191-205; 1999); los diferentes trabajos de Lefkowitz (1976:181-189; 1978:459-469; 1991; 2012:30-37); también Kivilo (2010:87-133). Igualmente importantes en el tratamiento del 'yo' en Arquíloco como en Hiponacte aparecen los respectivos estudios de Miralles; Pòrtulas $(1983 ; 1988)$. Asimismo, es necesario destacar la edición y traducción de Suárez de la Torre (2002), cuyo estudio previo recoge y analiza esta perspectiva crítica acerca del 'yo' en la poesía yámbica en general y cada uno de los poetas en particular.

2. Véase Greimas; Courtés (1990:225, 272), quienes toman los conceptos 'interlocutor/ interlocutario' y 'narrador/ narratario' de las respectivas teorizaciones de Ducrot (1984:251-277) y Genette (1989:270-321), y los utilizan para designar a los actantes de la enunciación enunciada cuando aparecen explícitamente instalados en el enunciado.
Al igual que la lírica y la elegía, el yambo griego arcaico (ss. VII-VI a.C.) es un género de carácter subjetivo. El poeta yámbico, en contraposición al aedo homérico, emplea en su enunciación predominantemente la primera persona. Esta primera persona, empero, presenta diferentes facetas y se constituye en expresión de manifestaciones de tonalidad variada, como emociones y sentimientos íntimos, juicios de valor, opiniones y puntos de vista de diversos temas, experiencias personales, bromas, exhortaciones a los compañeros, críticas e insultos a enemigos y adversarios, conocimientos de carácter general, y hasta reflexiones acerca de la propia función del poeta.

Desde hace algunas décadas se ha instalado un debate entre los estudiosos de la Antigüedad griega sobre el valor y la función que se le asigna al 'yo' en este tipo de composiciones. En términos generales, el interrogante que inaugura tal polémica es ¿quién dice 'yo' en un poema yámbico?, o ¿a quién refiere esa primera persona? Este cuestionamiento objeta las lecturas que, desde la propia Antigüedad, interpretaban que la primera persona en este tipo de composiciones refería directamente a la figura del poeta. La discusión, entonces, se pregunta si, en las producciones de los famosos poetas Arquíloco de Paros e Hiponacte de Éfeso, se trata de un 'yo' autobiográfico o, por el contrario, de un 'yo' convencional y ficticio, ${ }^{1}$ una dicotomía que, al decir de Gentili (1996:105), "debe analizarse en términos de semiología del discurso".

En vistas a aportar una respuesta a este debate, el presente trabajo tiene por objeto analizar en los ff. 19, 122, 196 y 196aW de Arquíloco de Paros, caracterizados particularmente por sus componentes de crítica e invectiva, los modos en que esa primera persona se inscribe en los enunciados y su funciones dentro de la instancia de enunciación poética, teniendo sobre todo en cuenta la naturaleza performativa y oral de la poesía griega arcaica.

\section{Los sujetos del discurso}

Es preciso distinguir, previamente a cualquier análisis, dos categorías de sujetos. Por un lado, los sujetos que se sitúan en un espacio extralingüístico y, a raíz de esto, extradiscursivo, es decir el poeta y el auditorio 'reales', que pueden ser contextualizados social e históricamente; y, por otro lado, los sujetos que se sitúan dentro del espacio lingüístico. Estos últimos se desdoblan, en primer lugar, en sujetos intralingüísticos e intradiscursivos (actantes del enunciado, denominados narrador y narratario o interlocutor e interlocutario, dependiendo del tipo de estructura comunicativa que se manifieste en el discurso), y, en segundo lugar, en sujetos intralingüísticos pero extradiscursivos (actantes de la enunciación, denominados enunciador y enunciatario). ${ }^{2}$

Si se toma un género poético en general o un conjunto de composiciones pertenecientes a un poeta en particular (por ejemplo, la poesía yámbica arcaica, o bien, los yambos de Arquíloco), esta distinción nos permite observar y describir las diversas manifestaciones del sujeto discursivo que caracteriza a un corpus y una performance poética determinada. Por este motivo, en una primera distinción, empleamos para nuestro análisis el nombre Arquíloco cada vez que nos referimos al sujeto extralingüístico, es decir, aquel poeta histórico y real, nacido en la isla de Paros hacia la primera mitad de siglo VII a. C., al cual se le atribuye la composición de poemas en versos elegíacos y 
yámbicos; en tanto que utilizamos su nombre entre comillas "Arquíloco" para referirnos específicamente al enunciador en los poemas yámbicos, es decir a aquel sujeto intralingüístico pero extradiscursivo, sujeto que se presupone virtualmente detrás de cualquier enunciado poético atribuido a Arquíloco. En una segunda distinción, intentaremos determinar en cada yambo cuál es la identidad de la primera persona que se inscribe deícticamente en el enunciado poético, es decir quién es ese sujeto intralingüístico e intradiscursivo a quien tradicionalmente se denomina persona loquens. Como veremos, la identidad de ese 'yo' inscripto en el enunciado no necesariamente refiere al enunciador poético "Arquíloco".

\section{Arquíloco y el carpintero Caronte}

Una buena forma de introducirnos en estas consideraciones podría ser examinar un pasaje de Aristóteles en el cual se describe el modo en que Arquíloco componía sus invectivas. Nos referimos a Retórica 1418.b.23-32, donde el estagirita discute acerca del carácter de los argumentos que se esgrimen en una deliberación o en un juicio, y señala que, debido a que hablar acerca de uno mismo puede provocar envidia y controversia o parecer palabrería excesiva, y hablar acerca de otro puede ser interpretado como una ofensa o grosería, es conveniente que, cuando una de las partes intente acusar o censurar a la otra, lo haga poniendo las palabras en boca de un tercero, tal

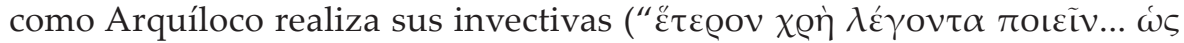

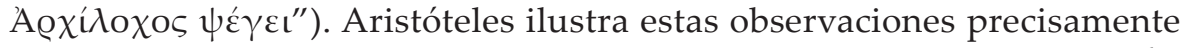
con dos composiciones del poeta de Paros, los fragmentos 122 y $19 \mathrm{~W}$ según transcribimos a continuación:

En lo que respecta al talante ("ก̂日oc"), como decir cosas de uno mismo puede

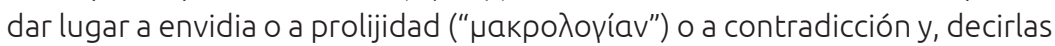
de otro, a injurias y a asperezas, es útil representar que es otra persona la que habla. Así lo hace Isócrates en el Filipo y en la Antídosis y éste es también el medio de que se sirve Arquíloco para sus censuras; como en aquel yambo en que, en efecto, hace que sea el padre quien diga de su hija:

"En asuntos de dinero, nada hay inesperado ni que se rehúse por un juramento"; y como <lo que hace decir > al carpintero Caronte, en el yambo que comienza:

"No a mí los < dominios> de Giges..."

<Otro ejemplo es lo que dice> Hemón, según Sófocles, a su padre en favor de Antígona, como si fueran otros quienes lo dijesen. ${ }^{3}$

Este pasaje de Aristóteles aporta dos datos fundamentales para el análisis de nuestros presupuestos acerca de la distinción del sujeto discursivo. En primer lugar, nos informa que la voz que aparece en el fr. $122 \mathrm{~W}$ de Arquíloco es la de un padre hablando acerca de su propia hija, y quien habla en el fr. $19 \mathrm{~W}$ es la del carpintero Caronte. Es decir, en ambos casos las marcas de la primera persona inscriptas en el enunciado no remitirían a "Arquíloco" en tanto enunciador, sino a Caronte o a un padre, respectivamente.

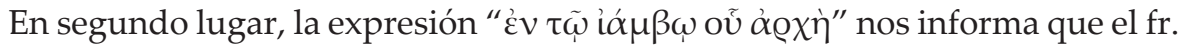
${ }_{19} \mathrm{~W}$ comenzaba precisamente con el verso que él cita, es decir sin el empleo de las fórmulas típicas de introducción de discurso directo, presentes en la 
4. Acerca de las fórmulas introductorias o de finalización de un discurso referido en forma directa, véanse Edwards (1970:1-36), Olson (1994:141-151) y Beck (2008:162-183).

5. Sobre esta hipótesis, véase Tsagarakis (1977:32, 79-81)

6. Además de los pasajes de Aristóteles y de Plutarco, el fr. 19W ha sido citado por diferentes autores, entre ellos la información más Graeca 21.2.256.6; Et.Gud. 537.26 s.v. túpavvoc; y Anacreontea 8B.

7. Las traducciones de los fragmentos en griego nos pertenecen.

8. El mismo rechazo por la riqueza y el poder aparece en Anacreonte 19P (PMG 361) épica como en la elegía. ${ }^{4}$ Esta innovación estilística en el modo de iniciar las composiciones, sin indicar a quién pertenece la voz que se inscribe en el enunciado, nos conduce a considerar que tal vez también otros fragmentos yámbicos de Arquíloco podrían contener un 'yo' que refiere a una persona loquens diferente a la de "Arquíloco" (como efectivamente sucede con Caronte o con ese padre que habla de su hija). ${ }^{5}$

Estos dos poemas de Arquíloco citados por Aristóteles han sido conservados también por otras fuentes. En efecto, debemos a Plutarco (De tranquilitate animi $470 \mathrm{~b}-\mathrm{c}$ ) la totalidad de los trímetros yámbicos que hoy se conocen del fr. 19W:

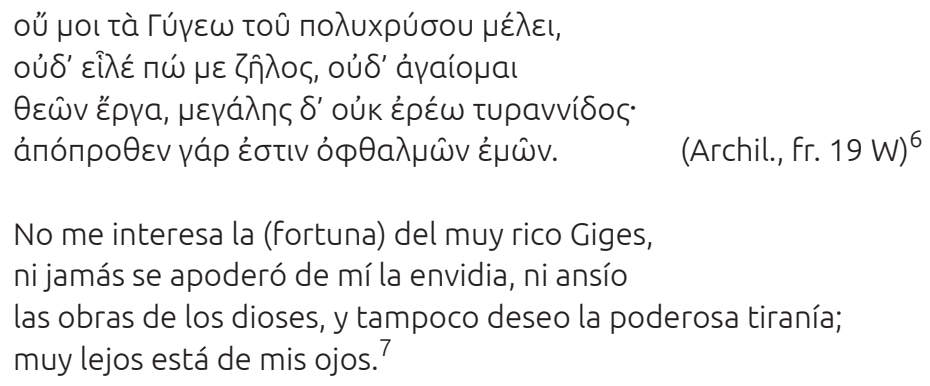

Manifestando una actitud totalmente desprendida, el carpintero Caronte afirma no tener interés por las riquezas del famoso rey lidio Giges, ni sentir envidia, ni ansiar las obras de los dioses, ni tampoco la tiranía poderosa. Tal austeridad parecería estar reproduciendo la sabiduría tradicional de máximas o proverbios. ${ }^{8}$ Sin embargo, su falta de ambición de poder y de bienes materiales, rayana en la candidez, también podría ser comprendida de manera irónica. El desinterés del carpintero por lo material y mundano, en esta dirección, implicaría necesariamente un encomio a la austeridad al modo de un exemplum didáctico. Como señala Vox (1998:113-118), podría tener una estrecha relación con las enseñanzas transmitidas por Hesíodo, pero de una manera irónica, como un "sottile contrappunto alla dottrina arcaica testimoniata nei Lavori e i giorni esiodei." En ese sentido, la mímesis en clave irónica permite postular un total distanciamiento entre la voz de Caronte (el interlocutor inscripto en el enunciado poético), y la de "Arquíloco" (el enunciador yámbico). Si es posible sostener que el carpintero asume como propias las enseñanzas sobre la austeridad y la moderación, es necesario suponer entonces que "Arquíloco" hace oír esa voz ante su auditorio con alguna intención, y es muy probable que con el fin de ridiculizarla. Recordemos que el discurso mimético rara vez es neutral.

Lamentablemente, ni el pasaje de Retórica que cita parte de este yambo ni el resto conservado nos permiten conocer contra quién estaba dirigida la invectiva ( $\psi$ ó $\gamma \circ \varsigma$ ) típica del género. Sin embargo, si fuera posible argumentar que se trata de una ironía contra una forma de pensar ingenua y sencilla, las críticas podrían tener como destinatarios a aquellos que encarnan esa forma de pensar, representados aquí bajo un personaje típico, Caronte; o también podría tratarse de una persona real e histórica, coetánea del poeta, que aparece disfrazada en el yambo con la máscara de este personaje. ${ }^{9} \mathrm{O}$ quizás la invectiva, en vez de estar dirigida contra la ingenuidad y candidez de pensamiento, tuviese como destinatario a alguien rico y poderoso, alguna suerte de 'pequeño Giges' local. También se ha propuesto otra lectura, que valiéndose de la relación planteada entre el yambo y el poema de Hesíodo, a lo mejor Caronte esté dirigiendo una crítica contra 
otro carpintero, tal como podría deducirse a partir de Trabajos y días 25-26:

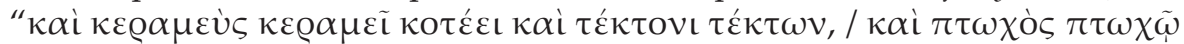

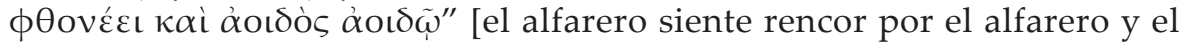
carpintero por el carpintero, el mendigo envidia al mendigo y el aedo al aedo]. ${ }^{10}$ El posible vínculo entre el yambo de Arquíloco y estos versos de Hesíodo, que habrían tenido su origen en un proverbio tradicional, ${ }^{11}$ nos llevaría a considerar que figurativamente el destinatario de la invectiva pudiera haber sido realmente otro poeta, que es censurado aquí a causa de su envidia y su resentimiento.

En cuanto al fr. 122W, también citado por Aristóteles, se conserva de la siguiente manera:

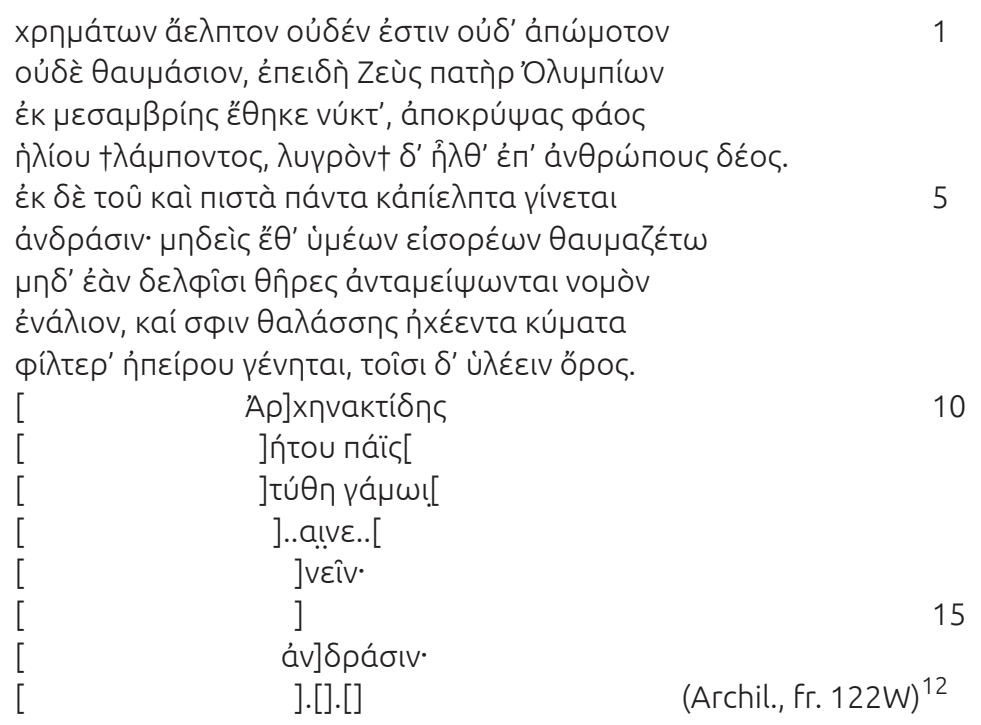

Del mismo modo que el fr. $19 \mathrm{~W}$, este yambo también parece reproducir un tipo de saber tradicional de carácter general. El motivo, en este caso, tiene su origen en la referencia a un eclipse: desde que Zeus ocultó el sol en pleno día, nada hay inesperado ni sorprendente para los hombres, ni aun si vemos que los animales terrestres comienzan a habitar las profundidades marinas, o si a los delfines les resulta más agradable el bosque que el mar. ${ }^{13} \mathrm{El}$ tono se asemeja

\section{Cfr. Vox (1998:118).}

11. West (1978) señala que probablemente los versos 25-26 de Trabajos y días pertenezcan a un proverbio tradicional muy anterior a Hesíodo; cfr. Verdenius (1982:28)

12. El fragmento ha sido transmitido por Estobeo 4.46.10, al cual se le sumó posteriormente el P.Oxy. 2313 fr.1.a.
13. La posible alusión a un eclipse solar ha servido para establecer la cronología relativa de Arquíloco. Entre los eclipses constatados en Paros durante el transcurso del s. VII a.C., se considera que aquí se hace alusión al que se produjo en el año 647 a.C. Рara los eclipses en relación a este yambo y para la cronología de Arquíloco, véanse Jacoby (1941:97-109); Rankin (1977a:24-25) y (1977b:5-15). 
14. Un comentario al pasaje de Aristóteles, Comm. in Arist. Graeca

21.2.255.31, nos transmite dos interpretaciones acerca del poema de Arquíloco: en la primera, el escoliasta señala que se trataría de la respuesta que da un padre a alguien que enrostra la fealdad de su hija (Continúa en página 19.)

15. La lectura de Lasserre (1947:1-7) se apoya principalmente en dos argumentos: en primer lugar, señala que el artículo de "tòv natépa" transmitido en el pasaje de Retórica"ne peut avoir d'autre valeur que celle d'un possessif",

es decir, al tratarse de un sustantivo

de parentesco, Aristóteles estaría enfatizando que Arquíloco hace hablar 'al/a su' padre. (Continúa en página 19.)

16. La tradición biográfica sobre la relación entre Arquíloco y Neobule, la hija de Licambes, puede reconstruirse a partir de diferentes fuentes antiguas, véanse por ejemplo Orígenes Cels. 2.21K.; Dio Cr. 74.16; AP 7.69, 71, 351 y 352: Hor. Ep. 1.19.30 y Epod. 6.11-14 con Pseudacron Schol. ad loc. (=T 26G); Mart. 7.12.6; Ov. Ib. 53-54 y Schol. C ad loc. (=T 29G); Ib. 521-4 y Schol. ad loc.

(=T 31G); Eust. 11.277 (1684.45). (Continúa en página 19.)

17. Esta hipótesis ya había sido postulada por Immisch (1890:198-203); desarrollada posteriormente por Jurenka (1900:13): Hauvette (1905:75): Fränkel

(1924:81); Friedländer (1929:379).

Véanse también Treu (1968:146); Rodríguez Adrados (1976:212).

18. Ante la falta de datos certeros, Bossi (1990:179) aconseja que lo más conveniente sería "rinunciare del tutto a un'identificazione".

19. Pickard-Cambridge (1966:15) tradu-

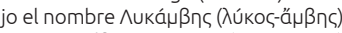
como "wolf's gait". West (1974:22-28) ha sostenido que este nombre se vincula con los cultos de Dioniso y de Deméter, ya que el formante -auß-pue-

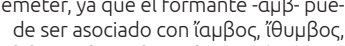

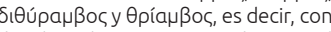
el ámbito dionisíaco. E, igualmente, el nombre comparte su raíz con 'láußn, la mítica esclava del rey Céleo que hizo reír a Deméter (h.Cer. 200-204). (Continúa en página 19.)

20. Seguramente Aristóteles conocía el texto completo de estos yambos, y si se considera que Hor. Ep. 2.68: "haec ubi locutus faenerator Alfius", podría estar imitando a Arquíloco, se puede sostener la hipótesis de pus los pom identidad de ambos personajes era revelada. De cualquier modo, la forma de comunicación poética en el período arcaico era muy diferente a la de la época de Horacio La ejecución ora del yambo ante un reducido auditorio de amigos en el contexto del simposio arcaico seguramente no requería hacer explícita la identidad de las personae loquentes para comprender de quiénes se trataba; por el contrario es probable que la explicitación de los nombres fuera una información redundante e innecesaria y quitara efectividad a la revelación. De manera diferente sucede con la poesía escrita, ya que se vale de otros recursos discursivos para que la identidad de esa primera persona pueda ser develada por los lectores. al de la sobriedad característica de la lamentación, o bien a la justificación reflexiva ante acontecimientos inesperados o sorprendentes, que se explican a partir de la intervención divina.

De acuerdo con Aristóteles, en este fragmento Arquíloco nos haría escuchar a un padre hablando en primera persona acerca de su propia hija. ${ }^{14}$ En la búsqueda de otorgarles identidad a los actores involucrados en el poema, la información que aporta Aristóteles ha sido interpretada de diversas maneras. Lasserre (1947), por ejemplo, ha considerado que la persona loquens es el propio padre del poeta, quien estaría reprobando la excesiva manifestación de dolor de su hija (la hermana de Arquíloco) por la muerte de su marido en un naufragio. ${ }^{15}$ Es decir, el poeta utilizaría la máscara de su propio padre reprendiendo a la hija, cuando en realidad la recriminación está dirigida contra un

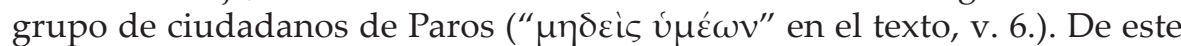
modo, se evitaría la confrontación directa y ellos no podrían reprobar la soberbia de Arquíloco.

Peek (1956), en cambio, ha identificado al padre y a la hija con Licambes y Neobule, dos personajes cuya presencia es frecuente en la obra del poeta. De esa manera, el fragmento aludiría a la conflictiva relación que supuestamente Arquíloco mantuvo con los licámbidas, particularmente después de que el 'padre Licambes' decidiera romper el compromiso matrimonial entre el poeta y una de sus hijas, Neobule. ${ }^{16}$ Aunque esta interpretación ya había sido insinuada anteriormente por otros autores, ${ }^{17}$ sin dudas es Peek (1956:2) quien, tras el descubrimiento y la edición del P.Oxy. 2313 fr.1.a, y en atención a la palabra $\gamma \alpha \dot{\alpha} \mu \omega$ ! del v. 12, argumenta claramente en favor de esta hipótesis.

Sin embargo, la aparición, años más tarde, del fr. 196aW (publicado en 1974) posibilitó una nueva interpretación, ya que en ese poema un narrador en primera persona relata a un amigo un encuentro erótico con la hija menor de

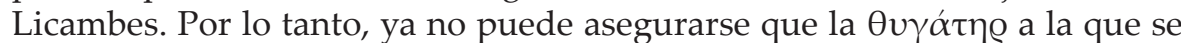
refiere Aristóteles sea Neobule, sino que podría tratarse igualmente de su hermana menor. Si este fuera el caso, Licambes podría estar hablando tal vez sobre la conducta sexual de su hija más pequeña, que es seducida en el fr. 196aW, en lo que sería la exposición pública de las conductas individuales de los integrantes de esta familia. ${ }^{18}$

Como puede observarse, ya sea que se trate de Neobule o de su hermana menor, es muy tentador atribuirle la identidad de Licambes a aquel padre que, de acuerdo con Aristóteles, habla en primera persona acerca de su hija. Sin

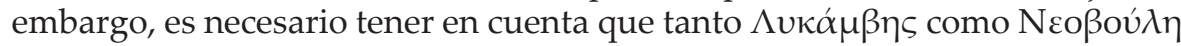
podrían ser nombres parlantes creados ad hoc por el poeta para aludir, tal vez, a personas reales dentro de la comunidad, del mismo modo que posteriormente Aristófanes empleó sobrenombres para satirizar a personajes históricos bien conocidos por el público ateniense. ${ }^{19}$

Esto nos lleva a concluir que la información transmitida por Aristóteles acerca del empleo de personae loquentes (información que, por otro lado, ha sido conservada únicamente en esta fuente) ${ }^{20}$ resulta fundamental para determinar el modo en que se constituye enunciativamente el sujeto del discurso poético en estos yambos. Sin el pasaje de Retórica se podría cometer el error de referenciar directamente la deixis de primera persona a la figura del poeta, interpretando ambos fragmentos como una expresión en clave personal y autobiográfica, tal como parece haber procedido, entre otros, el sofista Critias en su lectura de 
los poemas de Arquíloco. ${ }^{21}$ Sin duda los ejemplos de Arquíloco tomados por Aristóteles resultan una voz de alerta ante la interpretación que entiende mecánicamente como autorreferenciales todas las manifestaciones en primera persona que aparecen en el corpus yámbico del poeta de Paros.

Ahora bien, desde la moderna perspectiva teórica del análisis del discurso es posible deslindar los diferentes niveles enunciativos que entran en juego en estos poemas. Aunque presentan algunas diferencias, los dos yambos pueden ser considerados bajo una misma estructura de enunciación, que esquematizamos de la siguiente manera:

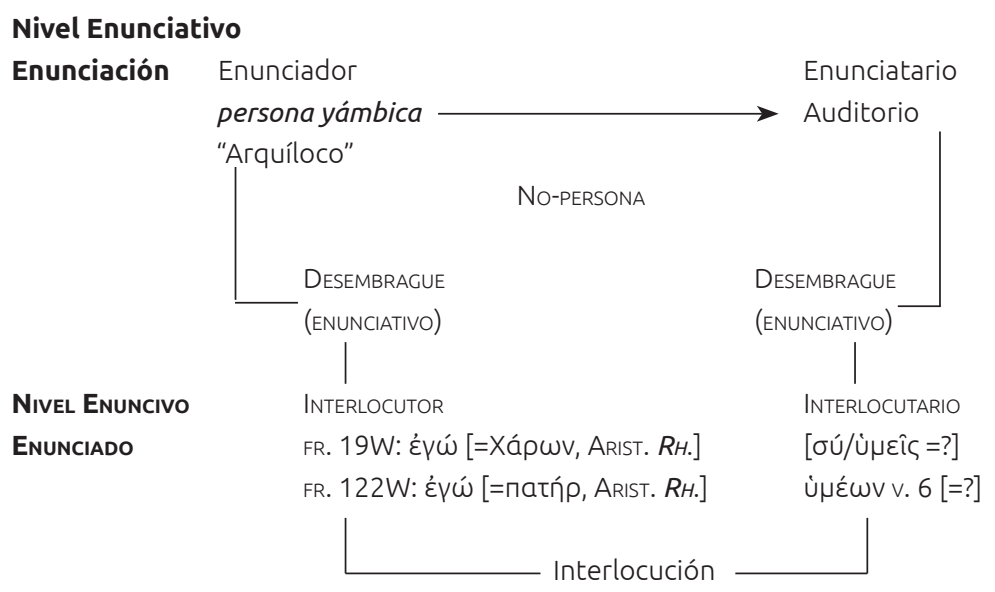

Si bien la escenografía enunciativa de ambas composiciones es idéntica, hay algunas diferencias en la forma de apertura discursiva. En primer lugar, debemos señalar que los dos presentan una estructura comunicativa de interlocución, la cual implica una situación dialógica y presupone la existencia de dos posiciones actanciales: interlocutor e interlocutario. ${ }^{22}$

El primero de estos poemas, fr. $19 \mathrm{~W}$, se inicia con un desembrague de tipo enunciativo que instala en el discurso las formas de la enunciación enunciada ('yo'-'tú/ustedes'). En este yambo, el interlocutor se inscribe deícticamente en el enunciado a través de los pronombres $\mu \mathrm{ol}$ (v. 1), $\mu \varepsilon$ (v. 2), y $\dot{\varepsilon} \mu \tilde{\omega} \nu$ (v. 4); y también por medio de las marcas de primera persona de los verbos $\alpha \gamma \alpha i ́$ í $\alpha$ เ (v. 2) y $\dot{\varepsilon} \mathrm{e} \omega($ v. 3). Por su parte, el interlocutario no aparece explícitamente en el enunciado, pero se presupone en reciprocidad solidaria con el interlocutor. ${ }^{23}$

El segundo, fr. $122 \mathrm{~W}$, en cambio, comienza en realidad con un desembrague de tipo enuncivo que inaugura en el discurso las formas del enunciado referido u objetivado ('él/ella/ello'). Pero en el v. 6 se inicia un nuevo enunciado, esta vez por medio de un desembrague enunciativo que, ahora sí, inscribe en el discurso a los actantes de la enunciación enunciada. En este caso el interlocutor no aparece marcado deícticamente en el texto, pero se presupone implícitamente en el discurso por solidaridad recíproca con el interlocutario, inscripto a través de la deixis pronominal $u ́ \mu \varepsilon ́ \omega v\left(\right.$ v. 6). ${ }^{24}$

El esquema pone en evidencia, además, que entre la identidad de los interlocutores de ambos yambos (Caronte y el padre, respectivamente) y la identidad del enunciador yámbico "Arquíloco" se establece una relación de no concomitancia. En este punto, es muy importante considerar que las máscaras de Caronte y del padre pertenecen al nivel enuncivo, no al nivel
21. Según Eliano, VH10.13 (=Critias 88B 44DK), Critias decía que Arquíloco hablaba muy mal de sí mismo ("kákı غ̇autòv हînعv"), porque si el poeta no lo hubiera hecho público, nadie se habría enterado de que era hijo de la esclava

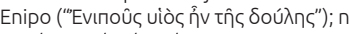
que luego de abandonar Paros a causa de la pobreza y la escasez se dirigió a

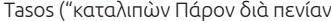

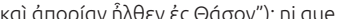
una vez allí, se convirtió en enemigo de

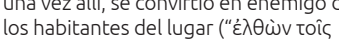

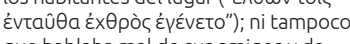
que hablaba mal de sus amigos y de sus enemigos ("ònoíws toù фí̉ ouc

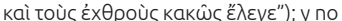
se habŕ sabido que era un adúltero " "म

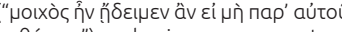

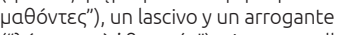

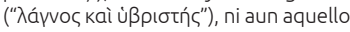
que es más vergonzoso, que arrojó

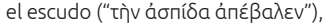
si él mismo no lo hubiera dicho.

Estas acusaciones provienen de una lectura literal y autobiográfica hecha por Critias de los propios poemas de Arquíloco, ya que todo lo que enumera podría rastrearse en los fragmentos que se han conservado hasta hoy.
22. Tomo el concepto de 'dialógico' en el sentido que le otorga Kerbrat-Orecchioni. Esta autora (1990:15) propone distinguir entre "interlocución dialogal", que se aplica a la interacción conversacional, e "interlocución dialógica", que se aplica a los discursos que no esperan respuesta pero que ponen en escena varias voces, es decir, que son polifónicos.

23. A raíz de esto, para el fr. $19 \mathrm{~W}$ hemos colocado en el esquema del lado del interlocutario los pronombres en segunda persona entre corchetes y su identidad con un signo de interrogación

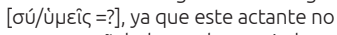
aparece señalado en el enunciado a través de la deixis, ni tampoco su identidad se manifiesta de manera explícita.

24. Por este, para el fr. $122 \mathrm{~W}$ hemos colocado del lado del interlocutario el pronombre ùnźwv y su identidad con un signo de interrogación entre corchetes, ya que si bien este actante aparece señalado deícticamente, su identidad no se manifiesta de manera explícita. 
25. En relación al Himno a Afrodita (fr. 1V) de Safo, Calame (1995:12-14) advierte que el investigador moderno, al trabajar con 'textos escritos' de la poesía griega arcaica y sin la presencia de situaciones enunciativas observables, cituris enunciado al 'acto ilocutorio' y perder de vista los 'efectos perlocutorios'; lo cual significa, en cierta forma, perder de vista que la poesía de este período es una poesía de ocasión una poesía cuya significación depende del contexto pragmático de producción y ejecución. enunciativo, es decir ellas son atributos, formas de enmascaramiento (tal vez las más ficcionales), que tiene el enunciador "Arquíloco" para manifestarse en sus yambos.

Por otro lado, la información transmitida por Aristóteles también nos permite indagar acerca de la finalidad de invectiva que él le atribuye a estos yambos. $\mathrm{Al}$ respecto, los textos de los poemas no parecen contener ningún elemento

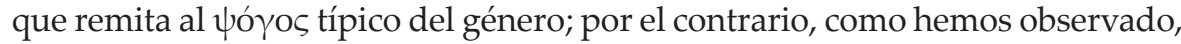
el fr. 19W parecería expresar una actitud de total desprendimiento frente a la vanidad de la riqueza y del poder, y el tono del fr. $122 \mathrm{~W}$ transmite, por su parte, cierta justificación y resignación ante las determinaciones divinas. Sin embargo, en tanto actos ilocutorios, las expresiones de desprendimiento y de lamentación reflexiva pertenecen al nivel enuncivo, al plano de la interlocución, es decir, estas actitudes con respecto a los discursos deben ser atribuidas a Caronte y a ese padre. En el plano enunciativo, es decir en el plano de comunicación entre "Arquíloco" y su auditorio, parece evidente que se produce otro tipo de acto ilocutorio o que la constatación de lo enunciado (como sucede con la ironía) genera un efecto perlocutorio totalmente diferente a lo que podría esperarse en una lectura literal de los textos. ${ }^{25} \mathrm{Y}$ es aquí donde podría residir el carácter invectivo que Aristóteles le atribuye a estos yambos, dirigidos contra personas de la comunidad que encarnan determinadas formas de pensar o actuar. El artilugio de esta máscara tendría a su vez una finalidad muy clara, la de evitar la confrontación mediante un ataque directo y, al mismo tiempo, arremeter de manera más incisiva contra sus adversarios por medio de la sátira burlona.

\section{Arquíloco y las hijas de Licambes}

Es lógico suponer, a partir de lo expuesto, que en la instancia de performance poética el auditorio-enunciatario era capaz de distinguir los diferentes planos discursivos, y podía interpretar la presencia de una persona loquens determinada sin la necesidad de que su identidad apareciera explícitamente revelada en el texto. Esto nos lleva a considerar, entonces, que el empleo de una máscara como la de Caronte o la del padre era un dispositivo enunciativo legitimado por el género yámbico del período arcaico. Es decir, "Arquíloco", en tanto enunciador yámbico, tenía la facultad de realizar un proceso de enmascaramiento del 'yo' en la instancia de performance poética.

Si esto es así como postulamos, la misma reflexión debería aplicarse al resto de las composiciones yámbicas del autor en que aparece igualmente una primera persona. Permítasenos analizar, a modo de ejemplo, los ff. 196 y 196aW, que podrían haber formado parte de una misma composición y que del mismo modo que el fr. $122 \mathrm{~W}$ involucra nuevamente a la ya mencionada familia de Licambes. ${ }^{26}$ En el primero de ellos, que posiblemente constituía el incipit de este yambo, tenemos una primera persona ocupando la posición actancial de interlocutor, la cual se dirige a un amigo (interlocutario) para confesarle que se encuentra preso del deseo sexual. Aunque de este fragmento se ha conservado una sola línea, el texto del epodo se completa tras el descubrimiento y la edición del fr. 196aW, más conocido como Primer Epodo de Colonia. En este último, esa misma primera persona ocupa ahora la posición de narrador y le cuenta a ese mismo amigo (narratario) el encuentro que mantuvo con la hija más pequeña de Licambes. En su relato le transmite la conversación que mantuvo con la joven, en la cual ataca y 
ridiculiza a la hermana mayor, Neobule, por su disipada conducta sexual. Una crítica que tiene, entonces, dos auditorios, la hermana menor, cuyo nombre no aparece, el auditorio en general. El poema termina finalmente con una descripción del encuentro sexual entre el 'yo' narrador y la muchacha, en los prados que rodean al santuario de Hera. Transcribimos aquí los ff. 196 y $196 a W$ :

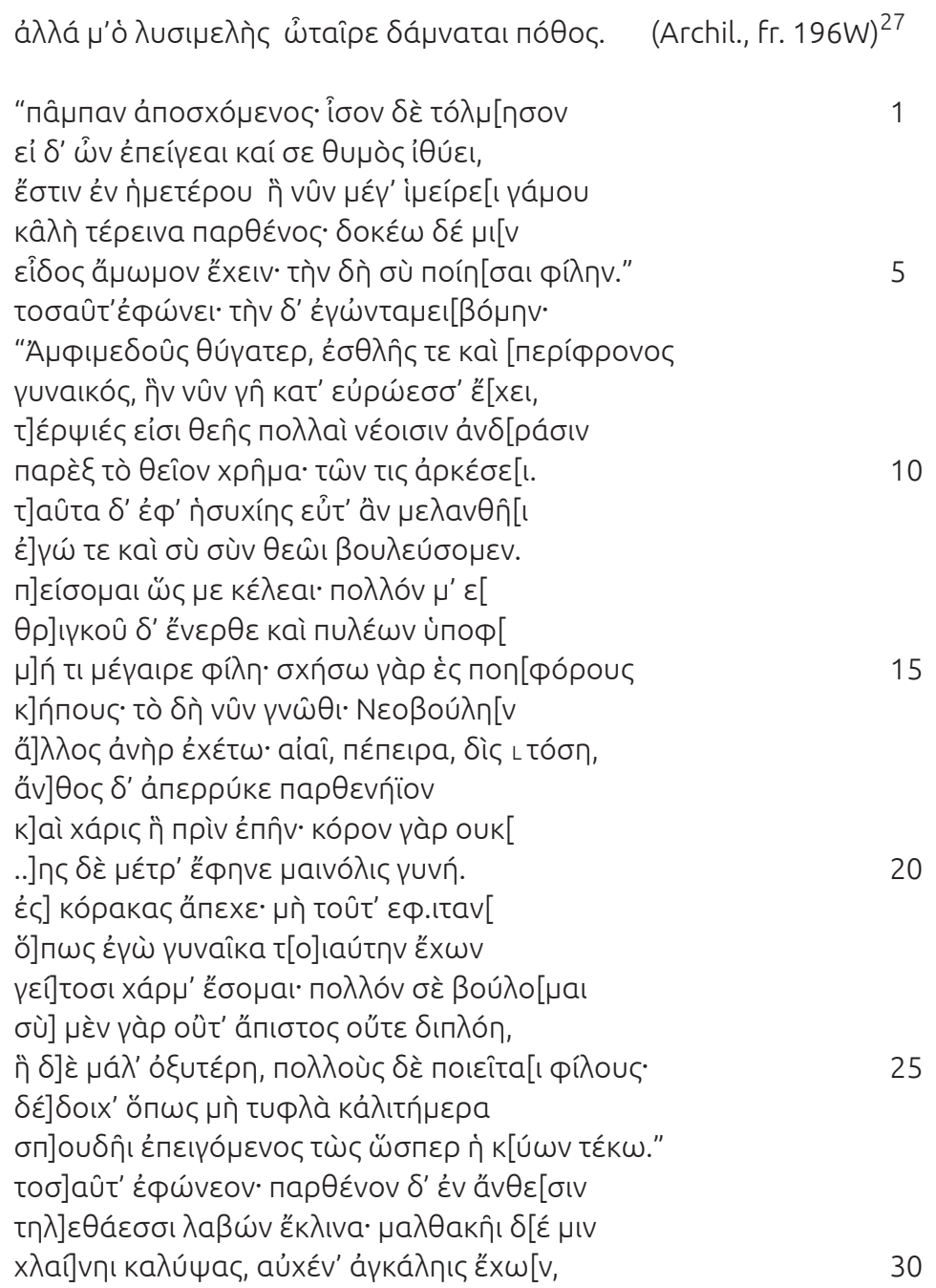

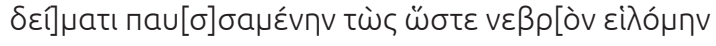

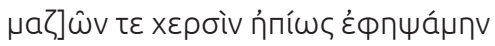

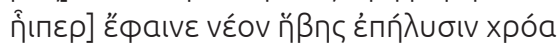

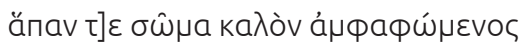

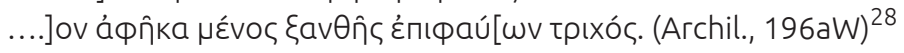

pero a mí, amigo, me somete el deseo que afloja los miembros.

(...)

“...absteniéndote por completo e igualmente aguántate.

Pero si estás apurado y te oprime la pasión,

hay en nuestra casa una que siente gran deseo de casarse,

joven hermosa y tierna. Y considero que

tiene una belleza inmaculada. Haz que ella sea tu amiga."

Estas cosas decía, y yo le respondí:

"Hija de Anfimedo, noble y [prudente

mujer, a quien ahora la húmeda tierra cubre,

28. Transmitido por el

27. Este fragmento ha sido transmitido por Hefestión 50.14-7 para ejemplificar el verso asinárteto compuesto por hemíepes y dímetro yámbico ("áouváptntov

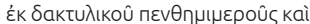

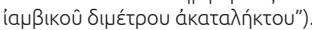


29. Véase nota 16. La tradición posterior presenta además a las hijas de Licambes acusando a Arquíloco por sus difamaciones y negando haberse encontrado a solas con él “Nosotras, las hijas de Licambes (...) juramos por los dioses y espíritus que jamás vimos a Arquíloco ni en las calles ni en el gran santuario de Hera", dicen las muchachas en el epigrama de Dioscórides, $A P 7.351$. Y en el epigrama atribuido a Meleagro, $A P 7.352$, afirman: "Juramos por la mano derecha del dios Hades y por el oscuro lecho de Perséfone que nadie puede decir que no seamos verdaderamente vírgenes, incluso debajo de la tierra. Pero el odioso Arquíloco muchas vergüenzas vomitó contra nuestra virginidad". Véanse también P.Dublin inv.193aB; AP7.71 (Gaet.); AP7.69 (Jul.). placeres de la diosa hay muchos para los hombres jóvenes aparte del divino asunto. Cualquiera de ellos será suficiente. Pero estas cosas con calma, cuando se vuelva negro [... tú y yo con un dios lo decidiremos.

Obedeceré como me ordenes. Mucho me [excita el deseo (?).

Debajo del cercado y de las puertas [que me precipite no rehúses, amiga, pues atracaré en el herboso jardín, ten presente eso ahora mismo. ¡A Neobule que otro hombre la posea! ¡Ay!, demasiado madura está, te dobla (en edad), la flor de su doncellez ha desaparecido y el encanto que antes poseía, pues saciedad [no tuvo. (?) Ya ha exhibido la medida su [vigor (?)] esa enloquecida mujer ¡Apártala a los cuervos! Que eso no [... Que yo, por tener semejante mujer, no me convierta en regodeo de los vecinos. Mucho más te prefiero, pues tú no eres infiel ni tienes doblez, en tanto que ella es inestable y hace amigos a muchos; tengo miedo que (hijos) ciegos y prematuros, apurado por el ansia, tal como una perra, engendre." Así le decía, y tomando a la joven, entre las incipientes flores la recosté. Luego de cubrirla con mi suave manto, mientras rodeaba su cuello con mis brazos, por el temor detenida como un cervatillo la tomé y dulcemente toqué con mis manos sus pechos, en donde] revelaba la fresca piel, encanto de juventud, y sintiendo [todo] su hermoso cuerpo, eyaculé mi [blan]co vigor mientras rozaba su rubio [vello. (?)

El poema pone de manifiesto dos elementos característicos de la poesía yámbica: por un lado, la temática erótica y sexual, y, por otro, la crítica y la invectiva dirigida contra un individuo. Como diversas fuentes antiguas parecen demostrarlo, particularmente aquellas que dan crédito a la leyenda de las difamaciones que Arquíloco habría llevado adelante contra Licambes y sus hijas, ${ }^{29}$ es posible que en este caso la identidad del 'yo' inscripto en el enunciado (interlocutor/narrador) sí se corresponda efectivamente con la del enunciador yámbico "Arquíloco". Esta vez partiremos inversamente que en los casos anteriores, planteando en primer lugar el esquema de la estructura enuncivo-enunciativa del fragmento en cuestión: 


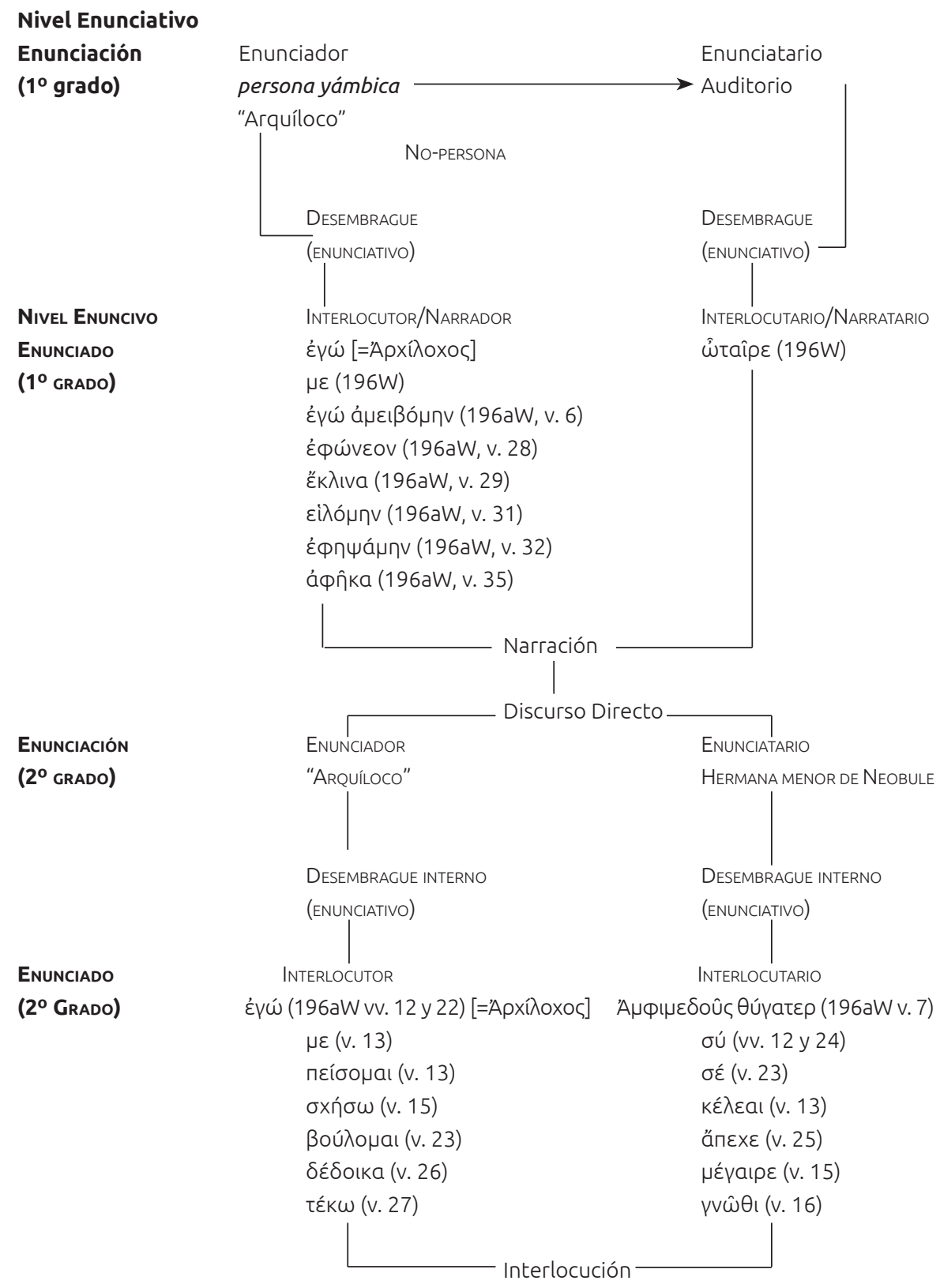

El esquema, fácil de ver, resulta más complejo, ya que presenta dos diferentes instancias de comunicación, que coinciden con los dos fragmentos. La primera, la que hemos denominado de $1^{\underline{0}}$ grado, muestra los actantes y actores en la instancia de comunicación poética. De este modo, se puede apreciar que el proceso de disyunción desde la enunciación hacia la del enunciado se produce a través de un desembrague enunciativo que instala en el discurso las formas de la enunciación enunciada. Dentro de este mismo nivel, el enunciado adquiere la forma de una escenografía de interlocución (fr. 196W), y de una escenografía narrativa (fr. 196aW). La posición actancial de interlocutor/narrador aparece ocupada de manera explícita por un elemento deíctico de primera persona singular: los pronombres " $\mu \varepsilon^{\prime \prime}$ ( $\left.196 \mathrm{~W}\right)$, en función de complemento paciente

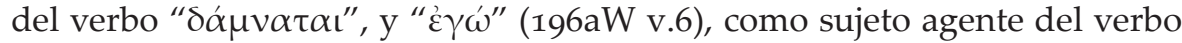
" $\alpha \mu \varepsilon \iota ß o ́ \mu \eta \nu$ "; y también por las marcas de primera persona singular de los

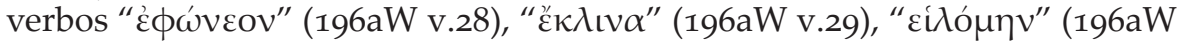

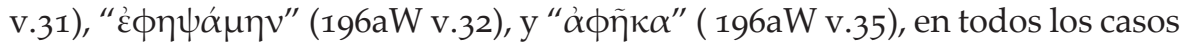


30. Maingueneau (2010:182-183) señala que mediante el discurso directo se establecen dos situaciones de enunciación con dominios enunciativos autónomos, con sus propias personas, deícticos y marcas de subjetividad: "La du DD est la dissociation entre les deux situations d'énonciation, citante et citée, qui fait coexister deux domaines énonciatifs autonomes: chacun conserve son JE, son $\mathrm{TU}$, ses repérages déictiques, ses marques de subjectivité propres. (...) Alors que les déictiques du discours citant sont directement interprétables grâce à leur situation d'énonciation, ceux du discours citéne peuvent l'être qu'à partir des indications fournies par ce discours citant." Los dos dominios enunciativos podrían describirse de la siguiente manera: un enunciador de primer grado (E1) dirige un enunciado, cuya modalidad discursiva produce un efecto de objetividad, un enunciatario (e1) en una situación de enunciación (S1), anclada en el tiempo (T1) y el lugar (L1) de la instancia enunciativa primaria. Dentro de este enunciado, E1 introduce por medio del discurso directo una situación de enunciación de segundo grado (S2), en la que un nuevo enunciador (E2) dirige la que un nuevo enunciador (E2) dirige (e2), en el T2 y L2 propio de la instancia enunciativa secundaria. Esta nueva situación de enunciación se manifiesta bajo una modalidad subjetiva, ya que el discurso presenta las marcas de los actantes de la enunciación que, al estar inscriptos en el enunciado y al tratarse de una estructura de interlocución, analizamos nuevamente bajo los conceptos de interlocutor e interlocutario. como sujeto agente. La identidad de esta primera persona podría mantener una relación de concomitancia con la identidad del enunciador, por esta razón el

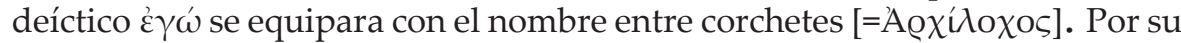
parte, si bien la posición actancial de interlocutario/narratario no se inscribe deícticamente en el enunciado, sí aparece ocupada de manera explícita a través

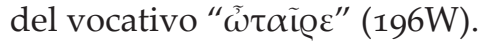

La posición actancial de objeto, por su parte, es ocupada por la narración del encuentro que el narrador mantuvo con la hija menor de Licambes. A través de un verbum dicendi se introduce en la narración un discurso referido en forma directa, lo cual inaugura una nueva situación de comunicación (indicada en el esquema como de $2^{\underline{o}}$ grado), que se corresponde con el diálogo producido en este encuentro. Por lo tanto, la introducción de un discurso directo produce una disociación de dos situaciones de enunciación autónomas: la primaria o de $1^{\underline{o}}$ grado, situación original de la comunicación del yambo, y la secundaria o de $2^{\underline{o}}$ grado, situación comunicativa que se inaugura dentro del enunciado de $1^{\underline{o}}$ grado. Cada una de estas instancias enunciativas tiene su propio marco de enunciación, sus propios actantes, y sus propias referencias espaciales y temporales. ${ }^{30}$

Pero para que estos dos dominios enunciativos coexistan es necesario que se produzca un desembrague interno que permita desacoplar el sistema de referencias de la enunciación de $1^{\text {o }}$ grado, ligado al enunciador primario, y establecer un nuevo sistema de referencias propio de la enunciación de $2^{\underline{0}}$ grado. En este caso, el desembrague interno es de tipo enunciativo ya que vuelve a instalar en el enunciado de $2^{\underline{0}}$ grado las formas de la enunciación enunciada. En esta instancia de comunicación interna, la posición actancial de enunciador vuelve a estar ocupada por "Arquíloco", mientras que la de enunciatario aparece ahora ocupada por la hermana de Neobule.

Dentro de su diálogo, el interlocutor se inscribe a partir de diferentes marcas deícticas pronominales y verbales. En dos oportunidades por medio del pronombre $\dot{\varepsilon} \gamma \omega \dot{\omega}$ (196aW vv. 12 y 22), el primero de ellos funcionando junto

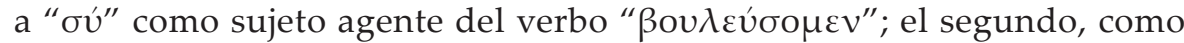

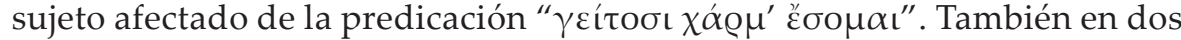
ocasiones está marcado deícticamente por el pronombre " $\mu \varepsilon^{\prime \prime}$ (ambos en el

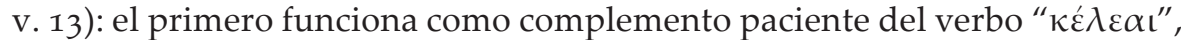

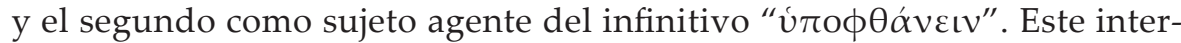
locutor también se manifiesta a través de los índices de primera persona

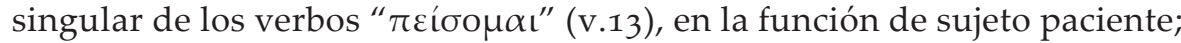

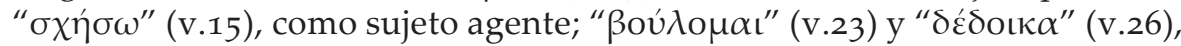
funcionando como sujeto experimentador; y " $\tau \dot{\varepsilon} \kappa \omega$ " (v.27), como sujeto paciente.

Por su parte, el interlocutario (es decir, la joven hija de Licambes) aparece inscripta a través de la deixis pronominal " $\sigma v^{\prime}$ " (vv. 12 y 24): en el primer caso, como hemos visto, funcionando junto a " $\varepsilon \gamma \omega \omega^{\prime \prime}$ como sujeto agente del verbo

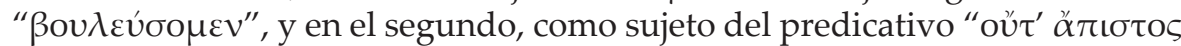

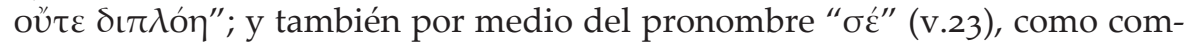

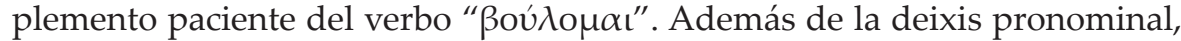
el interlocutario es señalado por la deixis de segunda persona singular de

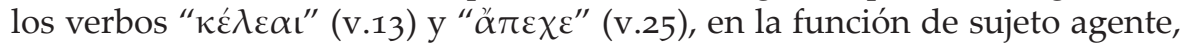

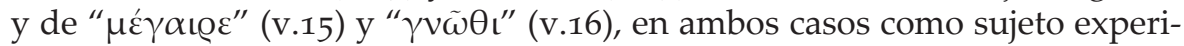
mentador. La identidad de este actante se hace explícita a través del vocativo

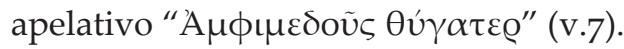


Recapitulando, digamos que la escenografía enunciativa que nos presenta este yambo es la de un narrador (identificado con "Arquíloco") que en primera persona se dirige a su narratario (un amigo suyo) para contarle los avatares del encuentro sexual con la más pequeña de las hijas de Licambes. Pero, como puede corroborarse en el esquema, la identidad de este narratario (en segunda persona singular) no se corresponde con la identidad del enunciatario que, obviamente, refiere al Auditorio, receptor natural de la performance yámbica. Este desdoblamiento en la instancia de recepción poética (por un lado, el narratario; por otro, el enunciatario), ${ }^{31}$ nos lleva a considerar que en este yambo la construcción de un narrador en primera persona también podría implicar un enmascaramiento del 'yo' con una función de $\psi \dot{\gamma} \gamma \varepsilon \iota v$ bien definida: publicitar de manera risible la conducta sexual de las hijas de Licambes frente al grupo de compañeros que formaban parte del simposio en que Arquíloco participaba.

Sin embargo, la exposición de las conductas individuales no debería llevarnos a deducir necesariamente que se trata de la comunicación de hechos que sucedieron realmente, ni siquiera se podría asegurar que los licámbidas en verdad han existido. Como hemos observado, Licambes y Neobule podrían ser nombres parlantes, como tal vez también lo sea el de Anfimedo, madre de las jóvenes. ${ }^{32} \mathrm{~A}$ lo mejor, como sostenía West, estos nombres remiten a personajes intervinientes en alguna suerte de entretenimiento tradicional con raíces en antiguas festividades religiosas. ${ }^{33} \mathrm{O}$ tal vez sean simplemente nombres creados por el poeta para ridiculizar y criticar a personas reales y coetáneas, que cada miembro de la hetería podía reconocer fácilmente.

Vale decir que, en los tres casos analizados, el análisis nos ha conducido a postular la existencia de procesos de enmascaramiento del 'yo' en los poemas de Arquíloco, particularmente en aquellos que apuntan a la crítica e invectiva, pero la observación bien podría hacerse extensiva al resto de las composiciones yámbicas destinadas a la performance dentro del contexto del simposio. ${ }^{34} \mathrm{Y}$ hasta sería posible postular, a nuestro modo de ver, que esta máscara discursivo-enunciativa haya tenido sus orígenes en aquellas otras máscaras materiales empleadas en las diferentes festividades comunitarias y ritos religiosos ligados a los cultos de Deméter y Dioniso, de los cuales se afirma recurrentemente que el yambo literario se ha desprendido, sobre la base, sobre todo, de compartir con ellos la invectiva, obscenidad y burla descarnada. ${ }^{35}$

\section{A modo de conclusión}

El concepto de 'persona yámbica' con el que hemos denominado al enunciador de estos poemas ( $c f r$. esquemas) nos ha permitido formalizar los procedimientos lingüísticos (pero extradiscursivos) que posibilitan los distintos tipos de enmascaramiento del 'yo' en las composiciones de Arquíloco estudiadas. Por 'persona yámbica' entendemos, entonces, un tipo de máscara enunciativa, particular de este género poético, que posibilita que el 'yo' inscripto en el enunciado pueda asumir diferentes roles. Estos roles pueden variar en diferentes grados de acuerdo con parámetros de ficcionalidad/no ficcionalidad. Así, la identidad de esta primera persona puede aparecer en una relación de no concomitancia con la identidad de esa 'persona yámbica' (como en los ff. 19 y $122 W$ ), o, por el contrario, de concomitancia (ff. 196 y 196aW). En el primer caso estaríamos ante la variable más ficcional del espectro, ya que la posición actancial que le corresponde al 'yo' aparece ocupada por un actor (Caronte o
31. Acerca de este desdoblamiento, Maingueneau (2010:339) señala: “Les énonciations proférées sur scène, on l'a vu, sont adressées à deux destinataires distincts: l'interlocuteur sur scène e le public. Le même discours doit donc agir sur l'interlocuteur immédiat et sur le destinataire indirect [...] En principe, les lois du discours concernent les seuls personnages. Mais elles doivent aussi, d'une certaine façon, être respectées à l'égard du spectateur". Si bien esta observación se refiere específicamente a la enunciación teatral, sin embargo también puede ser aplicada a otros tipos de presentaciones públicas, como por ejemplo la performance de los poemas yámbicos en la Grecia arcaica.

32. Degani (1977:42-43) señala:

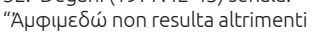
attestato ed è ben inteso da Koenen 500 como «colei che tutt'intorno si preocupa», epiteto dunque che si addice perfettamente ad una «umsichtige Frau»." El empleo de este nombre en el Primer epodo de Colonia podría tener un fin sarcástico. Aquella madre, "noble y prudente mujer" (v. 6), que protegía y velaba por sus hijas, yace "ahora cubierta por la húmeda tierra" (v. 7), por lo tanto, su pequeña hija en edad de pubertad está totalmente indefens ante el acecho sexual de los hombres. 33. West (1974:27): "The possibility ! am suggesting is that Lycambes and his libidinous daughters were not living contemporaries of Archilochus but stock characters in a traditional entertainment with some (perhaps forgotten) ritual basis".

34. Para un análisis más detallado del resto de las composiciones yámbicas de Arquíloco, así como también para el corpus yámbico de Hiponacte de Éfeso y de Calímaco de Cirene, remito a Carrizo (2017).

35. Para esta hipótesis, remito a Carrizo (2018a). 
36. Para la persona yámbica en Hiponacte, véase Carrizo (2018b). el padre que habla acerca de su hija) cuya voz toma una distancia mayor con respecto a la voz de la 'persona yámbica'. En el segundo, la correspondencia de identidad entre el 'yo' y la 'persona yámbica' produce una ilusión referencial. Esa primera persona parece remitir directamente a la propia figura del poeta en una suerte de expresión personal o autobiográfica, sin embargo su referencia nunca deja de ser sino una máscara construida con una función yámbica determinada, o sea, la 'persona yámbica' "Arquíloco".

El carácter ficcional del rol asumido por el 'yo' puede variar además en relación con la segunda persona inscripta en el enunciado, es decir, si el "tú/ustedes" que ocupa la posición actancial de interlocutario o de narratario se refiere a un nombre parlante, a una persona real en particular, o a los miembros del auditorio en la instancia de la performance poética.

A través del concepto de 'persona yámbica' hemos intentado describir un tipo singular de dispositivo poético que permite al enunciador de un yambo asumir ante su enunciatario diferentes roles en el enunciado poético. Una 'persona yámbica' en particular podría definirse por el conjunto de roles y rasgos que se manifiestan en un corpus yámbico determinado. Queremos decir, que se podrían delinear las características y funciones que definen a la 'persona yámbica' no solo de "Arquíloco", sino también, por ejemplo, la de "Hiponacte". ${ }^{36}$ 


\section{Notas}

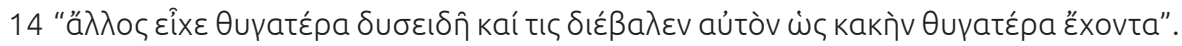
Aunque el comentario no lo explicita, se entrevé que el lamento del padre se debe a la falta de pretendientes de la hija. En la segunda, el escoliasta sostiene que el padre le está respondiendo a un pretendiente (el cual le reprocha la falta de dote) que no pierda las esperanzas de recibir alguna, ya que hasta lo más inespe-

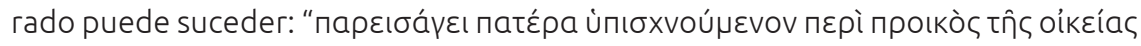

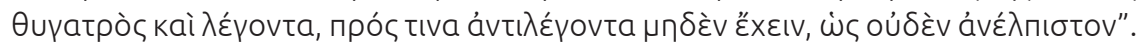
(Viene de página 10.)

15 En segundo lugar, Lasserre da por sentado que la causa de los lamentos de esa 'hija' se enuncia en los ff. 8-13W. En estos poemas, de acuerdo con la fuente que los trasmite (Plu. Quom. adolesc. aud. poet. deb. 23b.5 y 33a.11), el propio poeta expresa su aflicción "llorando al marido de la hermana, desaparecido en el mar, sin haber recibido la sepultura acostumbrada"; y unas líneas más adelante reitera este motivo: "Arquíloco (...) afligido por la muerte en el mar del marido de su hermana..." Sin embargo, este último argumento es cuestionable. Los pasajes citados por Plutarco pertenecen a versos elegíacos, no a yambos. Y, más allá de las similitudes temáticas compartidas entre ambas formas poéticas, es difícil conciliar la profunda aflicción transmitida en las elegías con la invectiva del fr. 122W. Advertido de esta dificultad, Lasserre (1947:2) concluye que la función de invectiva ( $\psi \varepsilon ́ y \varepsilon ı v)$ que Aristóteles le atribuye a este yambo debe ser entendida, meramente, como la violenta severidad con la que el padre se dirige a su hija. (Viene de página 10.)

16 En estos textos se dice que Licambes comprometió a su hija Neobule en casamiento con Arquíloco, ofreciéndole además la correspondiente dote. Pero, tiempo después, el padre de la joven rompió ese pacto y, en venganza, Arquíloco compuso poemas de invectiva ("maledicum carmen scripsit", Pseudacron Schol. ad Hor. Epod. 6.11-14) contra Licambes y sus hijas, haciendo que ellos se suicidaran. Sin embargo, como lo ha demostrado Lefkowitz $(1976 ; 1981 ; 1991 ; 2012)$, estas tradiciones biográficas tomaban su información de los propios poemas y no de fuentes historiográficas. Con respecto a Arquíloco, esta autora sostiene que la información sobre su vida transmitida por detractores, como Critias, o por sus apologetas, como Mnesiepes, Sóstenes y Demeas, proceden de la lectura que ellos mismos realizaron de la obra del poeta y no de documentos históricos, conformando lo que ella denomina "fictional biographies": "all the biographical 'data' we have about Archilochus (and for that matter, about every other archaic poet) was generated from Archilochus' poetry by critical speculation, starting in the fifth century. This means, of course, that the details of Archilochus' life as they have come down to us, no matter how plausible they may sound, were invented long after the fact." (1976:182). La apelación en vocativo del

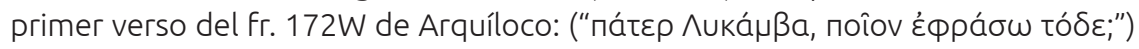
parece haber sido determinante para vincular al padre al que se refiere Aristóteles con Licambes. (Viene de página 10.)

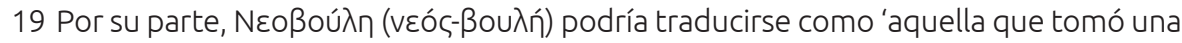
nueva decisión', tal vez la 'decisión' de casarse con otro. Van Sickle (1975:152) afirma: "We know that Archilochus shared the archaic alertness to the etymological fitness of names -'Neoboule' suits the kind of girl who changes her marriage plans." También, Degani (1977:42 n.64): "El nome [Neobule] designa evidentemente 'inconstanza." Sobre el empleo de los nombres parlantes en Arquíloco e Hiponacte, véase Bonanno (1980:65-88; 1993:31-60). Para esta autora, las personas reales a las que se ataca en 
los yambos "possono essere chiamati con un soprannome che allude non tanto al carattere di ciascuno, quanto alle note vicende che ne hanno rivelato il comportamento al resto della comunità" (1993:37). (Viene de página 10.) 


\section{Q Bibliografía}

\section{Ediciones y traducciones}

» Gerber, D. E. (1999). Greek Iambic Poetry. Cambridge-London: Harvard University Press.

» Racionero, Q. (1994). Aristóteles. Retórica. Madrid: Gredos.

»Suárez de la Torre, E. (2002). Yambógrafos griegos. Madrid: Gredos.

»West, M. L. (Ed.). (1998). Iambi et elegi ante Alexandrum cantati (3º ed.). Oxford: Clarendon Press.

\section{Bibliografía crítica}

» Beck, D. (2008). "Character-Quoted Directed Speech in the 'Iliad'”, Phoenix 62.1-2, 162-183.

» Bonanno, M. G. (1980). "Nomi e soprannomi archilochei”, MH37.2, 65-88.

" Bonanno, M. G. (1993). "Sull'identità dell'io lirico nella poesia greca arcaica". En: Amata, B. (ed.), Cultura e lingue classiche 3. Roma: L'Erma di Bretschneider, 31-60.

»Bossi, F. (1990). Studi su Archiloco. Bari: Adriatica Editrice.

" Bowie, E. L. (2001). "Early Greek lambic Poetry: The Importance of Narrative". En: Cavarzere, A.; Aloni, A.; Barchiesi, A. (eds.), Iambic Ideas: Essays on a Poetic Tradition from Archaic Greece to the Late Roman Empire. Lanham: Rowman and Littlefield, 127.

» Calame, C. (1995). The Craft of the Poetic Speech. Ithaca: Cornell University Press.

» Carey, C. (1986). "Archilochus and Lycambes", CQ 36, 60-67.

" Carey, C. (2010). "lambos". En: F. Budelmann (ed.), The Cambridge Companion to Greek Lyric. Cambridge: Cambridge University Press, 149-67.

»Carrizo, S. (2017). Persona yámbica. Procesos de enmascaramiento del 'yo' en la poesía yámbica de la Grecia arcaica y helenística (Tesis de Doctorado en Letras). Universidad Nacional de La Plata: La Plata, Buenos Aires. En: http://sedici.unlp.edu.ar/ handle/10915/66007; obtenido el 16/07/2018.

» Carrizo, S. (2018a). "Invectiva, burla, obscenidad: los orígenes rituales de la yambografía antigua”. Circe 22.1. En http://dx.doi.org/10.19137/circe-2018-220102

» Carrizo, S. (2018b). "'Persona yámbica' en Hiponacte: el caso de la máscara de suplicante". Synthesis 25.2. En: https://doi.org/10.24215/1851779Xe040

»Degani, E. (1977). "Sul nuovo Archiloco (Pap. Colon. inv. 7511)”, RCCM 1, 15-43.

»Degani, E. (2004 ). "Per una traduzione di Ipponatte". En: Albiani, M. G.; Alvoni, G.; Babieri, A.; Bossi, F.; Burzacchini, G.; Citti, F., Filologia e storia. Scritti di Enzo Degani. Hildesheim: Georg Olms, 101-112.

»Degani, E.; Burzacchini, G. (1977). Lirici greci. Anthologia. Firenze: La nuova Italia. 
"Dover, K. J. (1964). "The Poetry of Archilochos". Archiloque. Entretiens sur l'antiquité classique 10, 183-222.

» Ducrot, O. (1984). El decir y lo dicho. Buenos Aires: Hachette.

»Edwards, M. W. (1970). "Homeric Speech Introductions", HSPh 74, 1-36.

» Fränkel, H. F. (1924). "Eine Stileigenheit der frühgriechischen Literatur I und II", GGN, 63-127.

» Friedländer, P. (1929). "Retractationes", Hermes 64.2, 376-384.

» Genette, G. (1989). Figuras III. Barcelona: Lumen.

» Gentili, B. (1996). Poesía y público en la Grecia antigua. Barcelona: Quaderns Crema.

»Greimas, A. J. (1966). Sémantique structurale. Recherche de méthode. Paris: Larousse.

»Greimas, A. J. (1987). Semántica Estructural. Madrid: Gredos.

" Greimas, A. J.; Courtés, J. (1990). Semiótica. Diccionario razonado de la teoría del lenguaje (Vol. 1). Madrid: Gredos.

"Gremas, A. J.; Courtés, J. (1991). Semiótica. Diccionario razonado de la teoría del lenguaje (Vol. 2). Madrid: Gredos.

» Hauvette, A. H. (1905). Archiloque, sa vie et ses poesies. Paris: Albert Fontemoing.

» Immisch, O. (1890). "Zu griechischen Dichtern", Philologus 49, 198-203.

»Irwin, E. (1998). "Biography, fiction and the Archilochean ainos", JHS 118, 177-183.

» Jacoby, F. (1941). "The Date of Archilochos", CQ 35, 97-109.

» Jurenka, H. J. (1900). "Archilochos von Paros", Jahres-Bericht d. Maximilians-Gymn., 1-15.

» Kerbrat-Orecchioni, C. (1990). Les interactions verbales (3º ed., Vol. 1). Paris: Armand Colin.

» Kivilo, M. (2010). Early Greek Poets' Lives. The Shaping of the Tradition. Leiden \& Boston: Brill.

» Lasserre, F. (1947). "Le fragment 74 d'Archiloque", MH4, 1-7.

» Lefkowitz, M. R. (1976). "Fictions in Literary Biography: The New Poem and the Archilochus Legend", Arethusa 9.2, 181-189.

"Lefkowitz, M. R. (1978). "The Poet as Hero: Fifth-Century Autobiography and Subsequent Biographical Fiction", CQ 28, 459-469.

»Lefkowitz, M. R. (1991). First-Person Fictions: Pindar's Poetic 'l'. Oxford: Clarendon Press.

»Lefkowitz, M. R. (2012). The lives of the Greek poets ( $2^{\circ}$ ed.). Baltimore: The Johns Hopkins University Press.

" Maingueneau, D. (2010). Manuel de linguistique pour les textes littéraires. Paris: Armand Colin.

» Merkelbach, R.; West, M. L. (1974). "Ein Archilochos-Papyrus", ZPE 14, 97-113.

» Miralles, C.; Pòrtulas, J. (1983). Archilochus and the lambic Poetry. Roma: Edizioni dell'Ateneo.

» Miralles, C.; Pòrtulas, J. (1988). The Poetry of Hipponax. Roma: Edizioni dell'Ateneo.

» Nagy, G. (1976). "'lambos': Typologies of Invective and Praise”, Arethusa 2.9, 191-205. 
» Nagy, G. (1999). The Best of Achaeans. Concepts of the Hero in Archaic Greek Poetry ( $2^{\circ}$ ed.). Baltimore: The Johns Hopkins University Press.

»Olson, D. S. (1994). "Equivalent Speech-Introduction Formulae in the 'Iliad'”, Mnemosyne 47.2, 145-151.

»Peek, W. (1956). "Die Archilochos-Gedichte von Oxyrhynchos II", Philologus 100, 1-28.

» Pickard-Cambridge, A. W. (1966). Dithyramb Tragedy and Comedy (20 ed.). Oxford: Clarendon Press.

» Rankin, H. D. (1977a). Archilochus of Paros. New Jersey: Noyes Press.

» Rankin, H. D. (1977b). "Archilochus' Chronology and Some Possible Events of his Life", Eos 65, 5-15.

» Rodríguez Adrados, F. (1976). Orígenes de la lírica griega. Madrid: Biblioteca de la Revista de Occidente.

» Rösler, W. (1985). "Persona Reale o Persona Poetica? L'Interpretazione dell'lo nella Lirica Greca”, QUCC19, 131-144.

» Rotstein, A. (2010). The Idea of Iambos. Oxford: Oxford University Press.

» Slings, S. R. (Ed.). (1990). The Poet's I in Archaic Greek Lyric. Amsterdam: VU University Press.

» Treu, M. T. (1968). "Archilochos", RESuppl. 11, 136-156.

» Tsagarakis, O. (1977). Self-Expression in Early Greek Lyric Elegiac and lambic Poetry. Wiesbaden: Franz Steiner Verlag.

» Van Sickle, J. (1975b). "The New Erotic Fragment of Archilochus", QuCC20, 123-156.

» Verdenius, W. J. (1982). A Commentary on Hesiod Works and Days, vV. 1-382. Leiden.

» Vox, O. (1998). "Il poeta e il carpentiere (Archiloco e Carone)", QUCC29.2, 113-118.

» West, M. L. (ed.). (1966). Hesiod. Theogony. Oxford: Clarendon Press.

»West, M. L. (1974). Studies in Greek Elegy and lambus. Berlín; New York: Walter de Gruyter.

»West, M. L. (1975). "Archilochus Ludens: Epilogue of the Other Editor", ZPE 16, 217219.

»West, M. L. (1977). "Two Notes on the Cologne Epode of Archilochus", ZPE26, 44-48.

» West, M. L. (ed.). (1978). Hesiod. Works and Days. Oxford: Clarendon Press.

» West, M. L. (1993). Greek Lyric Poetry. Oxford: Oxford University Press.

» West, M. L. (1997). The East Face of Helicon. West Asiatic Elements in Greek Poetry and Myth. Oxford: Oxford University Press. 
